Article

\title{
Preference Construction Processes for Renewable Energies: Assessing the Influence of Sustainability Information and Decision Support Methods
}

\author{
Kiyotada Hayashi ${ }^{1, *}$, Hiroki Hondo ${ }^{2}$ and Yue Moriizumi ${ }^{2}$ \\ 1 Institute for Agro-Environmental Sciences, National Agriculture and Food Research Organization, \\ 3-1-3 Kannondai, Tsukuba, Ibaraki 305-8604, Japan \\ 2 Graduate School of Environment and Information Sciences, Yokohama National University, \\ 79-7 Tokiwadai, Hodogaya-ku, Yokohama 240-8501, Japan; hondo@ynu.ac.jp (H.H.); \\ yue-m@ynu.ac.jp (Y.M.) \\ * Correspondence: hayashi@affrc.go.jp; Tel.: +81-29-838-8221
}

Academic Editor: Gurkan Kumbaroglu

Received: 25 July 2016; Accepted: 28 October 2016; Published: 1 November 2016

\begin{abstract}
Sustainability information and decision support can be two important driving forces for making sustainable transitions in society. However, not enough knowledge is available on the effectiveness of these two factors. Here, we conducted an experimental study to support the hypotheses that acquisition of sustainability information and use of decision support methods consistently construct preferences for renewable power generation technologies that use solar power, wind power, small-scale hydroelectric power, geothermal power, wood biomass, or biogas as energy sources. The sustainability information was prepared using a renewable energy-focused input-output model of Japan and contained life cycle greenhouse gas emissions, electricity generation costs, and job creation. We measured rank-ordered preferences in the following four steps in experimental workshops conducted for municipal officials: provision of (1) energy-source names; (2) sustainability information; (3) additional explanation of public value; and (4) knowledge and techniques about multi-attribute value functions. The degree of changes in preference orders was evaluated using Spearman's rank correlation coefficient. The consistency of rank-ordered preferences among participants was determined by using the maximum eigenvalue for the coefficient matrix. The results show: (1) the individual preferences evolved drastically in response to the sustainability information and the decision support method; and (2) the rank-ordered preferences were more consistent during the preference construction processes. These results indicate that provision of sustainability information, coupled with decision support methods, is effective for decision making regarding renewable energies.
\end{abstract}

Keywords: renewable energy sources; preference construction; multiple criteria decision analysis; life cycle assessment; sustainability assessment

\section{Introduction}

Explicit appraisal of three dimensions in sustainability—environment, society, and economy-is the key to transitioning toward a renewable energy-based society [1,2]. For example, environmental problems such as global warming and biodiversity degradation are indispensable criteria for successful introduction of renewable energy into society. Furthermore, the social dimension has increased the importance in the assessment of energy technologies recently [3]. A typical example is labor issues, such as the use of child labor, although it is not limited to developing countries. Finally, economic sustainability should not be neglected in establishing a sustainable society, because profitable technologies for utilizing renewables are the foundation for sustainable transition. 
In operationalizing the assessment of sustainability, a decision support framework plays an important role [4]. Recent extension of life cycle assessment (LCA) into life cycle sustainability assessment (LCSA) [5] provides a good opportunity to understand the importance of the decision support framework. Although the relationship between decision analysis and LCA has already been discussed [6-8], the use of LCSA necessitates indicator-based assessment covering environmental, social, and economic pillars throughout entire supply chains. The plurality of indicators as development goals is important in designing regional energy strategies, as well as the plurality of alternative scenarios under multiple stakeholders [9].

However, perspectives on whether the provision or acquisition of sustainability indicators actually changes people's behavior are limited. Clarifying the influence of sustainability indicators on energy decision making is important in establishing democratic and science-based policymaking processes. In addition, perspectives on whether the use of the decision support framework changes people's behavior are limited. If simple provision or acquisition is not enough in improving energy decisions, it is necessary to apply decision support methods to use the sustainability indicators efficiently.

Therefore, we analyzed how people's decisions on renewable energies change in association with their knowledge on consequences of using renewable energy (whether they acquired sustainability information) and their knowledge on decision support (whether they studied how to use sustainability information).

\section{Hypotheses in Preference Construction Processes for Renewable Energies}

The Japanese public, for example, is not familiar with energy problems necessarily and it (including experts in energy sciences and politics) tends to exhibit unstable preferences in its energy decisions. Therefore, perspectives provided by the preference construction theory [10] are crucial in designing regional renewable energy scenarios. Preference construction has attracted much attention recently in a wide variety of research fields, including group processes, consumer choices, economic theory, and environmental valuation, because people, in general, construct preferences rather than revealing well-articulated, pre-stored, and retrievable preferences [10-14]. In this study, we focused our attention to preference construction in decisions made regarding renewable energies.

Despite the importance of preference construction, not enough research on such has been conducted in practical settings. One reason for this is that in LCA, the preferences are provided within the life cycle impact assessment (LCIA) as predetermined weights, which have already been prepared by LCIA methodology developers. LCA practitioners simply use the weights, although a typology based on sociology (cultural theory) is used in some LCIA methods (Eco-indicator 99 and $\mathrm{ReCiPe}$ ) to cope with the different views of stakeholders [15], providing a striking contrast to decision analysis such as structured decision making (SDM) [16].

We analyzed two types of changes in preference construction processes. One is the changes caused by provision of information, which is information acquisition from the perspective of decision makers. The problem is how the provision of sustainability information changes rank-ordered preferences regarding renewable energies. The other type of change is caused by the use of decision support methods. Here, we concentrated on how the use of multiple criteria decision analysis using value functions changes the rank-ordered preferences for renewable energies. Furthermore, we analyzed the changes in consistency of rank-ordered preferences among participants during preference construction processes.

\subsection{Rank-Ordered Preferences in Individual Participants}

People, in general, do not possess enough knowledge about renewable energies; instead, they make decisions using intuitive impressions empirically formulated from the limited information available to them. This corresponds to a situation where classical descriptive decision analysis was used to study heuristics and biases in human judgment [17]. This is the reason why deliberative polling involves information provision with group discussions [18]. Hence, acquiring sustainability 
information about a wide range of renewable power generation technologies will reconstruct understanding about the forms of renewable energy and change the rank-ordered preferences of these subjects.

Hypothesis 1. Provision of sustainability information changes rank-ordered preferences about renewable energy.

Sustainability information includes, in many cases, abstract indicators related to environmental, social, and economic pillars, and people have difficulty understanding the meaning of the indicators. The difficulties can be related to a dichotomy between public and private. Hence, acquiring supplemental explanation about sustainability information from another perspective (public and private values) will change their rank-ordered preferences.

Hypothesis 2. Provision of a supplemental explanation on sustainability information from a public-private perspective changes rank-ordered preferences regarding renewable energy.

Although information provision is expected to change rank-ordered preferences, the procedures to construct preferences are still based on heuristics. In general, when decisions are involved with complex preferences, major uncertainties, and important consequences, making decisions based entirely on intuition is not a useful process [19]. Hence, the use of methods to analyze and support decisions (formalized ways to construct preferences) will change rank-ordered preferences. It is known that the application of simple linear scoring rules improves the decisions [20].

Hypothesis 3. The use of decision support methods changes rank-ordered preferences for renewable energy.

\subsection{Consistency of Preferences among Participants}

We focused our attention in this study on individual decision making, and thus did not analyze group processes. That is, direct interactions among plural decision makers, and their impacts on preferences, in addition to group decision support methods such as decision conferencing [21], were outside the scope of this study. However, the provision of sustainability information and the use of decision support methods will change participant rank-ordered preferences in a coherent manner, and as a result, the differences in rank-ordered preferences among participants could become smaller.

Hypothesis 4. Rank-ordered preferences concerning renewable energy become consistent during the preference construction process with the provision of sustainability information and the use of decision support methods.

\section{Methods}

\subsection{Preference Elicitation through Organizing Workshops}

As a method to gather preferential data in hypothetical but realistic situations, we organized workshops to elicit the preferences of respondents in the city of Tsuru (Yamanashi Prefecture) on 6,13, and 14 November 2014. Municipal officials who had found employment one or two years previously were selected as participants (respondents, decision makers). The number of participants was 18 and the number of effective samples was 14, because not all participants were able to attend the whole workshops.

Among the 14 participants (effective samples), 6 participants began working in their current office in 2013 and the other 8 started in 2014. The average ages for the former and latter groups were 26.2 and 24.6 years, respectively. Three participants were female. Four participants worked for the Policy Formulation Division, which was responsible for organizing the workshop on the municipal office side. The participants worked in nine different divisions of the city government.

\subsection{Rank-Ordering of Power Generation Technologies Using Renewable Energy Sources}

The example decision problem we used in the workshop had six alternatives and three criteria. Participants in the workshop were asked to rank-order the alternatives, rather than to choose the most 
preferable alternative. Rank-ordering of alternatives was based on multiple criteria decision analysis and two types of cards, one simply provided the names of power generation technologies and the other provided attribute values (profiles) of the technologies.

The rank-ordered preferences of participants were determined for power generation technologies using renewable energy sources. These energy sources included solar power, wind power, small-scale hydroelectric power, geothermal power, wood biomass, and biogas, each of which is important in current Japanese energy policies [22].

The criteria by which to evaluate alternative power generation technologies using renewable energy sources were (1) life cycle greenhouse gas emissions $\left(\mathrm{kg}-\mathrm{CO}_{2}\right)$; (2) life cycle job creation (person-day); and (3) electricity generation costs (Yen). Each criterion was measured per the amount of electricity used by an average household annually $(4.8 \mathrm{MWh})$ and corresponded to an environmental, social, or economic aspect of sustainability.

The $6 \times 3$ evaluation matrix shown in Table 1 was tentatively prepared for use in the workshop and was made using a renewable energy-focused input-output model of Japan. The detailed calculation structure and more refined numerical values were provided from the final version of the renewable energy-focused input-output model [22]. During the workshop, we mentioned the contents of the table as sustainability information.

Table 1. The evaluation matrix used in the workshop.

\begin{tabular}{|c|c|c|c|}
\hline Criteria (Attribute) & $\begin{array}{c}\text { [Environment] } \mathrm{CO}_{2} \\
\text { Emissions }\end{array}$ & [Society] Job Creation & $\begin{array}{l}\text { [Economy] Electricity } \\
\text { Generation Costs }\end{array}$ \\
\hline Unit & $\mathrm{kg}-\mathrm{CO}_{2}$ & Person-day & Yen \\
\hline Solar & 182.4 & 3.40 & 177,600 \\
\hline Wind & 120.0 & 0.84 & 105,600 \\
\hline Small-scale hydroelectric & 153.1 & 1.73 & 163,200 \\
\hline Geothermal & 62.4 & 0.98 & 124,800 \\
\hline Wood biomass & 331.1 & 4.52 & 153,600 \\
\hline Biogas & 873.6 & 9.98 & 187,200 \\
\hline Range (Worst-Best) & $1000-0$ & $0-10$ & $200,000-100,000$ \\
\hline
\end{tabular}

\subsection{Decision Support Method}

We applied multiple criteria decision analysis based on multiple attribute value functions, which is commonly explained in textbooks on decision analysis [16,19,23-25] and is already discussed within the context of LCA [6-8]. For the sake of simplicity and because of limited time for the workshop, we assumed that all single attribute value functions were linear, and in addition, we set the attribute ranges beforehand (Table 1). Therefore, participants in the workshop could concentrate on the weighting procedure.

Weight elicitation, without taking into account the specific ranges of attribute values, is the most common mistake in the application of multiple attribute value functions $[19,26]$, and is not good preference construction practice [13]. Therefore, we used the weighting procedure with an appropriate range sensitivity of attribute weights, in which the swing weighting method and the indifference method based on difference value measurement were combined. The detailed weighting procedures are explained in Section 3.4 and Appendix A.

\subsection{Four-Step Procedure in the Workshop}

We conducted rank-ordering in four steps (Table 2).

Step 0. Participants intuitively rank-ordered the cards with the names of alternatives and related illustrations. An example of the cards with illustrations is shown in Figure 1. 
Step 1. Participants rank-ordered the cards with sustainability information (attribute value for each criterion), after attending a lecture on renewable energy technologies. An example of a card with sustainability information is shown in Figure 2. In the lecture, after showing an outline of energy consumption and characteristics of renewable energy technologies, the meanings of life cycle $\mathrm{CO}_{2}$ emissions, life cycle job creation, and life cycle electricity generation costs were explained. At the same time, cards with sustainability information were shown on the screen in the lecture room.

Step 2. Participants rank-ordered the cards with sustainability information once again, after getting a supplemental explanation about the differences in evaluation criteria from the perspective of public and private values. In the explanation, examples of public and private values in renewable energies and balancing of public and private values were illustrated.

Step 3. Weighting was conducted using the forms for weight elicitation and sticky tags, after attending a lecture on multiple criteria decision analysis and performing an exercise of weighting procedures. In the lecture, the difference between alternatives and criteria, the characteristics of the selection problem of power generation technologies, the concept of trade-offs and weighting, the calculation procedure of overall values, and the problems with weighting procedures without reference to attribute ranges were given.

Table 2. Four steps in the workshop.

\begin{tabular}{cccc}
\hline Step & Day & Information Provided & $\begin{array}{c}\text { Task for Decision Makers } \\
\text { (Respondents) }\end{array}$ \\
\hline 0 & Nov. 6 & Names of alternatives (technologies) & Rank-ordering of alternatives (cards) \\
1 & Nov. 6 & Attribute values for alternatives & $\begin{array}{c}\text { Rank-ordering of alternatives (cards) } \\
\text { Rank-ordering of alternatives (cards) } \\
2\end{array}$ \\
Nov. 13 & Explanation of public value & Weighting of the three attributes \\
\hline
\end{tabular}
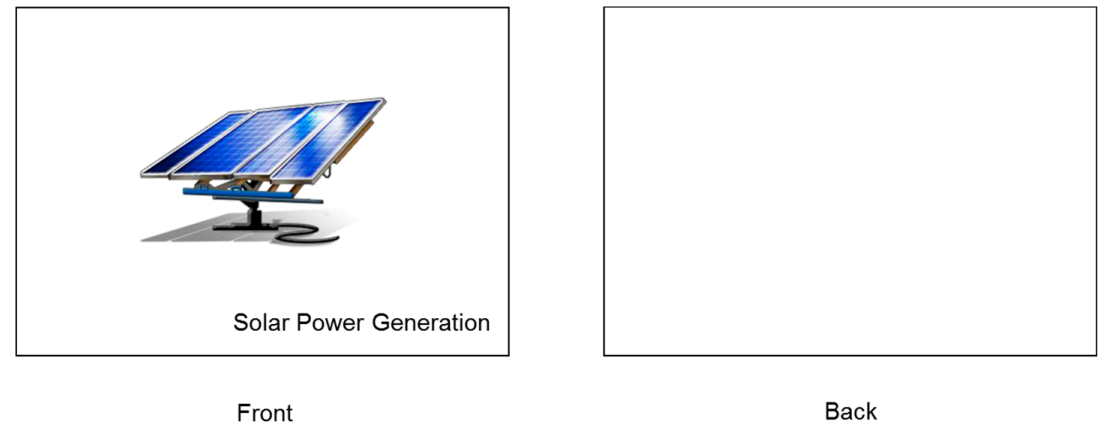

Figure 1. An example (solar power generation) card with illustration used in Step 0 . The back sides were blank. Japanese descriptions were used on the actual cards.

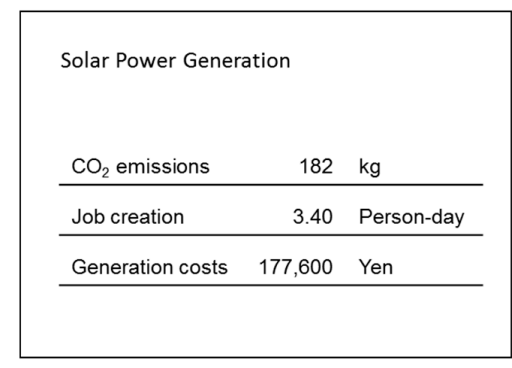

Front

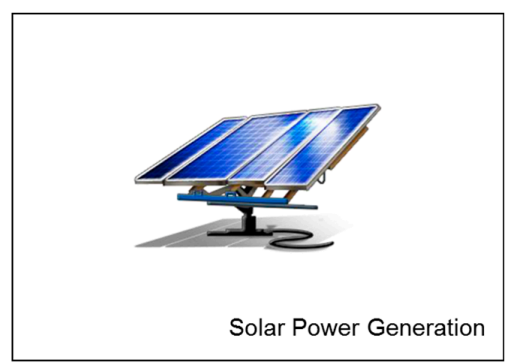

Back

Figure 2. An example (solar power generation) card with sustainability information used in Step 1. Japanese descriptions were used on the actual cards. 


\subsection{Weighting Procedure}

In the weighting procedure in Step 3, we used swing weighting and trade-off weighting (an indifference method) [27]. Both weighting methods take attribute ranges into account explicitly, and thus the range sensitivity of both methods is higher than weighting methods without reference to attribute ranges, such as direct weighting using simple scoring rules [28,29]. However, there are pros and cons for both methods used in this study. Swing weighting is suitable for getting overall structure, although it is less sensitive to the range. Weighting based on the concept of indifference is more sensitive, although understanding the concept of indifference is time-consuming. This is the reason why the two methods were used in a complementary way.

Step W1. Write the names of evaluation criteria, units, and attribute ranges on two types of sticky tags. One is a pentagonal arrow type and the other is a rectangular type. The former was used in Step W2 and the latter was used in Step W3.

Step W2. Put sticky tags on the 0-100 scale to measure weights. This step is equivalent to swing weighting $[16,19,25,27,30]$. The most important criterion was considered 100 as reference.

Step W3. Check the result of the weighting at Step W2 using the concept of indifference (trade-off weighting) [27,31]. Go back to Step W2 and revise the weighting if necessary.

Step W4. Calculate overall values and determine rank-orders. Go back to Step W2, if the result is unsatisfactory.

The details of this procedure are shown in Appendix A.

\subsection{Data Analysis}

\subsubsection{Degree of Deviation between Rank-Ordered Preferences}

To measure the degree of deviation between rank-ordered preferences for alternatives, we used the Spearman metric, which is equivalent to the Euclidean metric applied to rank vectors. We normalized the metric between 1 and 0 in this study. If the deviation between Steps $i$ and $i+1$ in Table 2 was 1 , the deviation was at its maximum; however, if the deviation was 0 , the deviation was at its minimum (the two rank-ordered preferences were identical).

\subsubsection{Measure of Consistency among Participants}

As an indicator to express the consistency of rank-ordered preferences among participants, we used the maximum eigenvalue for the Spearman's rank coefficient matrix. The larger the maximum eigenvalue, the more consistent the preferences were among the participants. In addition, to cope with small sample inferences, we used the resampling method of nonparametric bootstrapping $(10,000$ iterations) to estimate uncertainty (standard errors) in the eigenvalues.

\section{Results}

\subsection{Changes in Rank-Ordered Preferences of Individual Participants}

The degree of preference deviation between adjacent steps is illustrated for each participant in Figure 3 and the averages and standard deviations between adjacent steps are shown in Table 3. Preference orders of participants at Steps 0, 1, 2, and 3 are presented in Supplementary Tables S1-S4. From Step 0 to Step 1, rank-ordered preferences for most participants changed greatly. In other words, preference orders for renewable energy sources, which were formulated unconsciously, were changed as a result of the provision (acquisition) of sustainability information. The average degree of preference deviation was half of the complete change. Therefore, we judged that Hypothesis 1 was confirmed. 


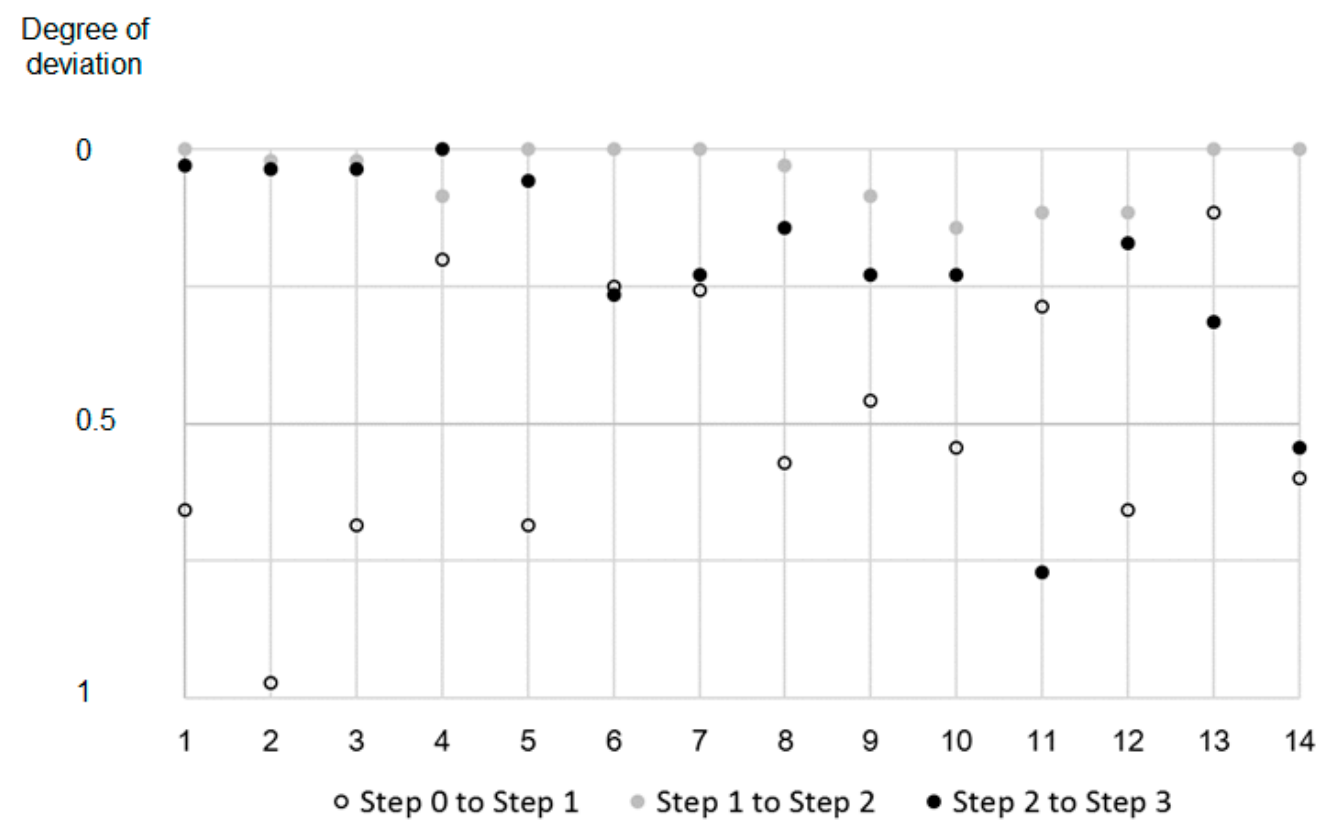

Figure 3. Participants' preferences between the steps. The degree of deviation between two adjacent steps is shown in the vertical axis. The numbers in the horizontal axis signify each of the 14 respondents.

Table 3. Averages of preference deviation between two adjacent steps.

\begin{tabular}{lcccc}
\hline & & Step 0 to Step 1 & Step 1 to Step 2 & Step 2 to Step 3 \\
\hline \multirow{2}{*}{ Degree of deviation $^{1}$} & Average & 0.496 & 0.045 & 0.216 \\
\cline { 2 - 4 } & Standard deviation & 0.242 & 0.052 & 0.217 \\
\hline
\end{tabular}

${ }^{1}$ The Spearman metric was normalized between 0 and 1 to show the degree of deviation between the two rank-ordered preferences.

In contrast, the changes from Step 1 to Step 2 were small. The average degree of deviation was 0.045 , with the maximum deviation only 0.143 . In addition, the differences among participants in the changes between steps were also small, as indicated by the small value of the standard deviation. Therefore, the provision of a supplemental explanation of evaluation criteria from the perspective of public and private interests did not cause major changes in rank-ordered preferences. Thus, we judged that Hypothesis 2 was not confirmed.

The changes from Step 2 to Step 3, which were caused by the use of the decision support method, were significant for participants 6 to 14, but not 1 to 5 . On average, the degree of the changes was almost half of that for the changes between Step 0 and Step 1 (information provision). We, therefore, judged that Hypothesis 3 was confirmed.

The details of the changes between Step 2 and Step 3 for participants 1-5 are illustrated in Figure 4. During the session, they practiced the weighting procedure several times and experienced how the rank-orders changed with the weights for the three criteria, by using the spreadsheet. As a result, only 0-2 couples in their rank-orders changed, as shown in Figure 4, and the degree of deviation between the two steps was small. 


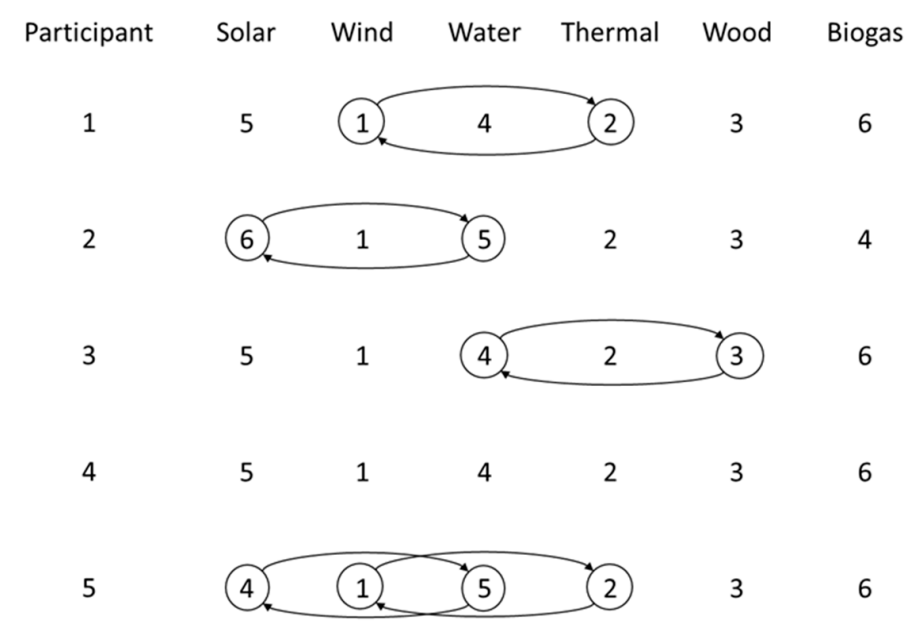

Figure 4. Rank-orders of the preferences for Step 3 and the differences between Step 2 and Step 3. Circles and arrows illustrate exchanges in the rank-orders.

\subsection{Increased Preference Consistency}

Changes in the preference consistency among participants, which was measured by the maximum eigenvalue for correlation coefficient matrices, are illustrated in Figure 5. It was revealed that the preference consistency among participants improved from Step 0 to Step 1 and from Step 2 to Step 3. There was a correspondence between changes in rank-ordered preferences and changes in preference consistency. We, therefore, judged that Hypothesis 4 was confirmed.

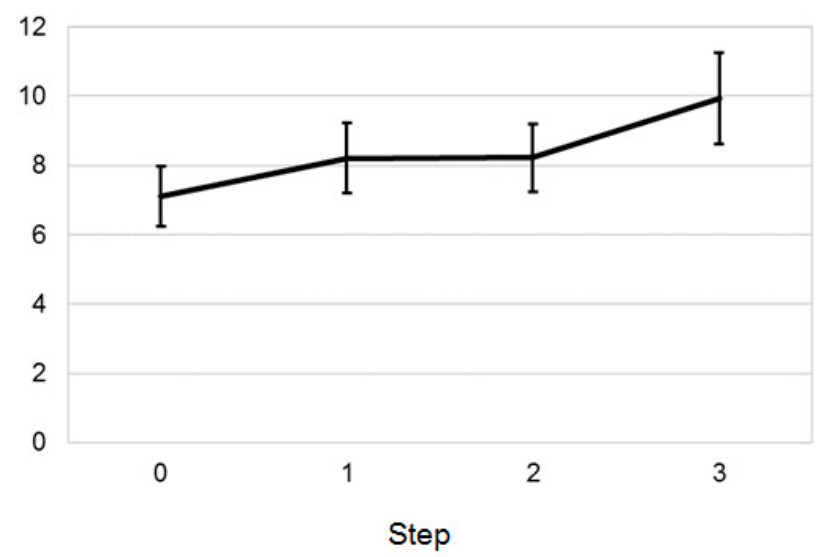

Figure 5. Changes in preference consistency: the maximum eigenvalues for the Spearman's rank-order correlation coefficient matrix $(14 \times 14)$. Nonparametric bootstrap means and standard errors (10,000 samples) are depicted.

\section{Discussion}

\subsection{Changes Caused by Information Provision}

The results of this study indicate that participant preferences were constructed through the acquisition of sustainability information and the use of a decision support method. This has the following implications. First, in policymaking processes, we have to recognize that the intentions of residents, which are used in policymaking processes to reflect preferences of residents, are changeable. The simple questionnaires typically used to survey preferences about, for example, renewable energy sources, only reveal temporal and shallow preferences. Therefore, information provision has to be coupled with the questionnaires to increase the understanding by the participants. 
This is consistent with recent findings on deliberative polling, which illustrated that deliberators changed their views significantly on immigration, climate change, and the EU [32]. This implies that public engagement prior to initiation of renewable energy projects is very important [33].

However, there is a caveat. Although we provided supplemental information on public value to make the problem more understandable, most participants did not change their rank-ordered preferences based on this information. There may be several reasons for this. One possibility is that there was conflict in the understanding and framing between the sustainability framework (a triangle of environment, society, and economy) and the public-private contrast. In other words, inconsistent duplication of evaluation criteria did not change the participant's preferences. Another reason may be that participants had already had implicit preferences on public-private issues and thus additional provision of the perspective on public value was redundant.

\subsection{Changes Caused by the Use of Decision Support Methods}

Although our results suggest that information provision (acquisition) is important in constructing preferences, the preferences further changed because of the use of the decision support method. That is, not only understanding numerical information on sustainability intuitively, but also using formalized decision support techniques for processing the numerical information, helped the decision makers formulate appropriate preferences. Therefore, recommendations to use sustainability information in policymaking processes regarding renewable energy sources need to be coupled with instructions on how to consistently process the information. It is important to notice that there is an educational implication in applying decision support methods. Even if rank-ordered preferences were not changed, applying decision support methods gives the participants an opportunity to think about whether their preferences were suitable or not.

\subsection{Increased Consistency during Preference Construction}

One of the important results in our study was that in parallel with the stepwise changes in preference construction processes for each participant, consistency among an individual's preferences improved. This means that information provision and decision support positively affected consensus building, although this study was limited to individual decision making. Because group discussions are expected to improve the preference consistency further, the simultaneous use of decision support methods and group discussions will be promising in real-world policymaking processes regarding renewable energy.

\subsection{Supporting Decisions through Preference Elicitation}

From the results of this study, we implied that, as compared with the use of predetermined weighting factors in integrating several environmental indicators (impact categories) as practiced in LCIA, applying decision support methods is also useful in assessing and designing, for example, future energy options based on renewables. A crucial point of this is that the application of decision support methods can be explicit about preference construction processes and is, therefore, suitable for participatory frameworks of renewable energy problems, in which a wide variety of participants, evaluation criteria, and future energy options are encompassed.

\section{Conclusions}

This study revealed that the provision of sustainability information and the use of a decision support method changed participant preference orders about renewable energy sources. Furthermore, the preference orders among participants become consistent during the workshops, which can be considered preference construction processes. Although these results have important implications for establishing participatory frameworks for better decision making concerning renewable energies, further studies are necessary to generalize our results. For example, this study is based on small 
samples of municipal officials and thus attention to other various stakeholders would be necessary, as well as an increased sample size.

Although we analyzed a predetermined problem (a sorting problem with three criteria and six alternatives) in order to determine the influence of the provision of sustainability information and the use of decision support methods, a study on how to structure the problem (problem structuring [34]) may be the key to setting up participatory frameworks. This would include two important topics. The first is how to invent effective criteria and includes reconsideration of life cycle sustainability assessment. Although the calculation of numerical values for the three criteria involves complicated processes, our attention to a wide range of sustainability criteria in sustainability assessment was limited. Therefore, future studies on how to identify and create better decision criteria are important. The second topic is how to develop creative alternatives. The combination of plural energy options and the definition of alternatives using geographic information will be important. Problem structuring in the real world inevitably involves group processes. We have to be explicit about how to involve stakeholders and how to support group decisions.

Supplementary Materials: The following are available online at www.mdpi.com/2071-1050/8/11/1114/s1, Table S1: Preference orders of participants at Step 0, Table S2: Preference orders of participants at Step 1, Table S3: Preference orders of participants at Step 2, Table S4: Preference orders of participants at Step 3.

Acknowledgments: This research was supported by the Environmental Research and Technology Development Fund (2-1302) from the Ministry of the Environment, Japan. We are grateful for the support from the municipal officials of the city of Tsuru, Yamanashi Prefecture. We also thank Aya Heiho and Ryota Ito of Yokohama National University for their contributions in organizing the workshops.

Author Contributions: K.H. and H.H. conceived and designed the experiments; K.H., H.H., and Y.M. performed the workshops; K.H. analyzed the data; and K.H. and H.H. wrote the paper.

Conflicts of Interest: The authors declare no conflict of interest. The founding sponsors had no role in the design of the study; in the collection, analyses, or interpretation of data; in the writing of the manuscript, and in the decision to publish the results.

\section{Appendix A}

This appendix illustrates details of the weighting procedure used in the workshops organized in the city of Tsuru, using an example.

Step W1. Write the names of the evaluation criteria, units, and attribute ranges on the two types of sticky tags as shown in Figure A1. The tags on the left are of the pentagonal arrow type and the tags on the right are of the rectangular type. The former was used in Step W2 and the latter was used in Step W3. At this step, we stated that each criterion was measured per the amount of electricity used by an average household annually.
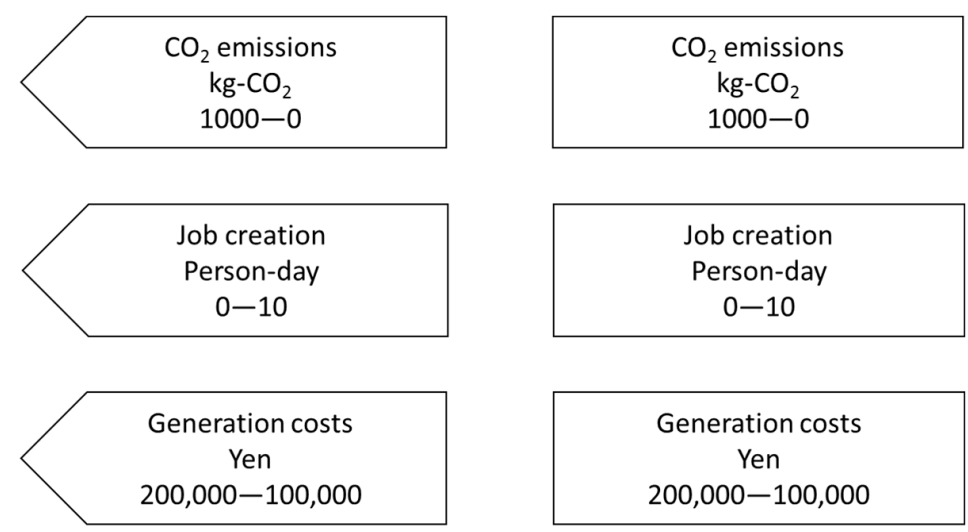

Figure A1. Sticky tags with the names of evaluation criteria, units, and attribute ranges, with value ranges from worst to best. 
Step W2. Put sticky tags on the 0-100 scale to measure weights. An example is shown in Figure A2. The weighting is practiced with reference to the attribute ranges; thus, it is equivalent to swing weighting. The most important criterion, "Generation costs" in the example, was 100 as reference.

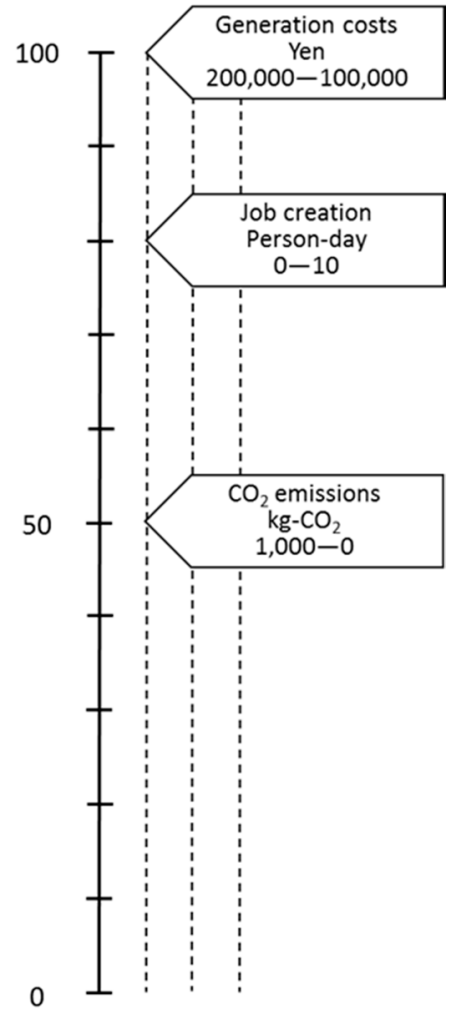

Figure A2. An example of weighting using sticky tags on the 0-100 scale.

Step W3. Check the result of the weighting at Step W2 using the concept of indifference as shown in Figure A3. Because the ratio of importance between "Generation costs" and "Job creation" is $100: 80$, the range $0-10$ for "Job creation" is indifferent to the range $200,000-120,000$ ( $80 \%$ of the original range) for "Generation costs". In this case, it is presumed that the decision maker thinks that the former (the range 0-10 for "Job creation") is indifferent to the range $200,000-140,000$ (60\% of the original range) for "Generation costs" as shown in Figure A4. Then, the decision maker goes back to the 0-100 scale and moves the sticky tag "Job creation" into the position "60" as illustrated in Figure A5.

Step W4. Calculate the overall values and determine the rank-orders. An Excel spreadsheet was used for summation, division, rank-ordering, and recoding of the calculation results. If the decision maker inputs weights for the three criteria, then he/she obtains overall values for each alternative, and the rank-order of alternatives, after clicking the calculation button. The decision maker goes back to Step W2, if the result is unsatisfactory to him/her. The spreadsheet can be used to record these trials by clicking the record button. The converged values are the weights of the decision maker. 

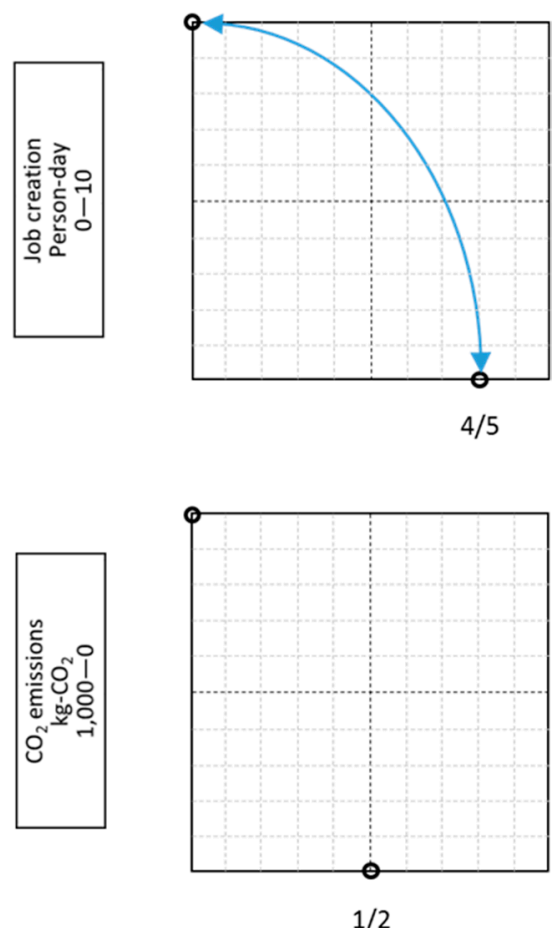

$$
\begin{gathered}
\text { Generation costs } \\
\text { Yen } \\
200,000-100,000
\end{gathered}
$$

Figure A3. An example of checking the weighting at Step W2 using the concept of indifference.
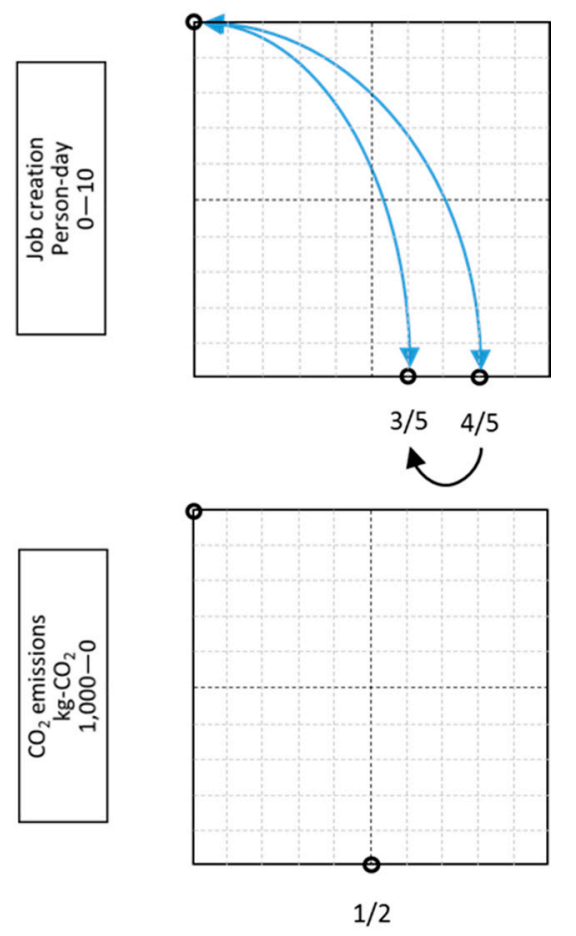

$$
\begin{gathered}
\text { Generation costs } \\
\text { Yen } \\
200,000-100,000
\end{gathered}
$$

Figure A4. An example of checking the weighting at Step W2 using the concept of indifference. A revised judgment from Figure A3. 


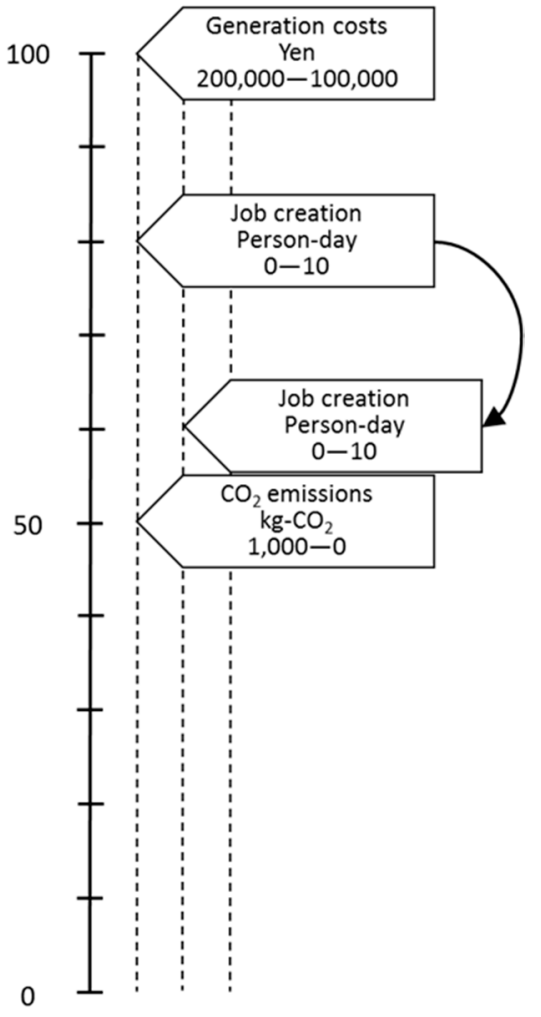

Figure A5. An example of weighting using sticky tags on the 0-100 scale. A revision based on the judgment shown in Figure A4. The dashed lines are used to distinguish the original judgment and the revised judgments.

\section{References}

1. Evans, A.; Strezov, V.; Evans, T.J. Assessment of sustainability indicators for renewable energy technologies. Renew. Sustain. Energy Rev. 2009, 13, 1082-1088. [CrossRef]

2. Morrison-Saunders, A.; Pope, J.; Bond, A. (Eds.) Handbook of Sustainability Assessment; Edward Elgar: Cheltenham, UK, 2015.

3. Gallego Carrera, D.; Mack, A. Sustainability assessment of energy technologies via social indicators: Results of a survey among European energy experts. Energy Policy 2010, 38, 1030-1039. [CrossRef]

4. Santoyo-Castelazo, E.; Azapagic, A. Sustainability assessment of energy systems: Integrating environmental, economic and social aspects. J. Clean. Prod. 2014, 80, 119-138. [CrossRef]

5. Finkbeiner, M.; Schau, E.M.; Lehmann, A.; Traverso, M. Towards life cycle sustainability assessment. Sustainability 2010, 2, 3309-3322. [CrossRef]

6. Hertwich, E.G.; Hammitt, J.K. A decision-analytic framework for impact assessment, Part I: LCA and decision analysis. Int. J. Life Cycle Assess. 2001, 262-272. [CrossRef]

7. Seppala, J.; Basson, L.; Norris, G.A. Decision analysis frameworks for life-cycle impact assessment. J. Ind. Ecol. 2002, 5, 45-68. [CrossRef]

8. Linkov, I.; Seager, T.P. Coupling multi-criteria decision analysis, life-cycle assessment, and risk assessment for emerging threats. Environ. Sci. Technol. 2011, 45, 5068-5074. [CrossRef] [PubMed]

9. Trutnevyte, E.; Stauffacher, M.; Schlegel, M.; Scholz, R.W. Context-specific energy strategies: Coupling energy system visions with feasible implementation scenarios. Environ. Sci. Technol. 2012, 46, 9240-9248. [CrossRef] [PubMed]

10. Lichtenstein, S.; Slovic, P. (Eds.) The Construction of Preference; Cambridge University Press: New York, NY, USA, 2006.

11. Slovic, P. The construction of preference. Am. Psychol. 1995, 50, 364-371. [CrossRef]

12. Bettman, J.R.; Luce, M.F.; Payne, J.W. Constructive consumer choice processes. J. Consum. Res. 1998, 25, 187-217. [CrossRef] 
13. Payne, J.W.; Bettman, J.R. Measuring constructed preferences: Towards a building code. J. Risk Uncertain. 1999, 19, 243-270. [CrossRef]

14. Milch, K.F.; Weber, E.U.; Appelt, K.C.; Handgraaf, M.J.J.; Krantz, D.H. From individual preference construction to group decisions: Framing effects and group processes. Organ. Behav. Hum. Decis. Process. 2009, 108, 242-255. [CrossRef]

15. Hofstetter, P.; Baumgartner, T.; Scholz, R.W. Modelling the valuesphere and the ecosphere: Integrating the decision makers' perspectives into LCA. Int. J. Life Cycle Assess. 2000, 5, 161-175. [CrossRef]

16. Gregory, R.; Failing, L.; Harstone, M.; Long, G.; McDaniels, T.; Ohlson, D. Structured Decision Making: A Practical Guide to Environmental Management Choices; Wiley-Blackwell: Chichester, UK, 2012.

17. Tversky, A.; Kahneman, D. Judgment under uncertainty: Heuristics and biases. In Judgment under Uncertainty: Heuristics and Biases; Kahneman, D., Slovic, P., Tversky, A., Eds.; Cambridge University Press: New York, NY, USA, 1982; pp. 3-20.

18. What Is Deliberative Polling ${ }^{\circledR}$ ? Available online: http://cdd.stanford.edu/what-is-deliberative-polling/ (accessed on 3 October 2015).

19. Parnell, G.S.; Bresnick, T.; Tani, S.N.; Johnson, E.R. Handbook of Decision Analysis; John Wiley \& Sons: Hoboken, NJ, USA, 2013.

20. Russo, J.E.; Shoemaker, P.J.H. Decision Traps: The Ten Barriers to Decision-Making and How to Overcome Them; Doubleday: New York, NY, USA, 1989.

21. Phillips, L.D. Decision conferencing. In Advances in Decision Analysis; Edwards, W., Miles, R., Von Winterfeldt, D., Eds.; Cambridge University Press: New York, NY, USA, 2007; pp. 375-398.

22. Moriizumi, Y.; Hondo, H.; Nakano, S. Development and Application of Renewable Energy-Focused Input-Output Table. J. Jpn. Inst. Energy 2015, 94, 1397-1413. [CrossRef]

23. Kirkwood, C.W. Strategic Decision Making: Multiobjective Decision Analysis with Spreadsheets; Duxbury Press: Belmont, CA, USA, 1996.

24. French, S.; Maule, J.; Papamichail, N. Decision Behaviour, Analysis and Support; Cambridge University Press: Cambridge, UK, 2009.

25. Goodwin, P.; Wright, G. Decision Analysis for Management Judgment, 5th ed.; John Wiley \& Sons: Chichester, UK, 2014.

26. Keeney, R.L. Common mistakes in making value trade-offs. Oper. Res. 2002, 50, 935-945. [CrossRef]

27. Von Winterfeldt, D.; Edwards, W. Decision Analysis and Behavioral Research; Cambridge University Press: New York, NY, USA, 1986.

28. Fischer, G.W. Range Sensitivity of Attribute Weights in Multiattribute Value Models. Organ. Behav. Hum. Decis. Process. 1995, 62, 252-266. [CrossRef]

29. Poyhonen, M.; Hamalainen, R.P. On the convergence of multiattribute weighting methods. Eur. J. Oper. Res. 2001, 129, 569-585. [CrossRef]

30. Belton, V.; Stewart, T. Multiple Criteria Decision Analysis: An Integrated Approach; Kluwer Academic Publishers: Norwell, MA, USA, 2002.

31. French, S. Decision Theory: An Introduction to the Mathematics of Rationality; Ellis Horwood: Chichester, UK, 1986.

32. Sanders, D. The effects of deliberative polling in an EU-wide experiment: Five mechanisms in search of an explanation. Br. J. Political Sci. 2012, 42, 617-640. [CrossRef]

33. Devine-Wright, P. (Ed.) Renewable Energy and the Public: From NIMBY to Participation; Earthscan: London, UK, 2011.

34. Midgley, G.; Cavana, R.Y.; Brocklesby, J.; Foote, J.L.; Wood, D.R.R.; Ahuriri-Driscoll, A. Towards a new framework for evaluating systemic problem structuring methods. Eur. J. Oper. Res. 2013, 229, 143-154. [CrossRef]

(C) 2016 by the authors; licensee MDPI, Basel, Switzerland. This article is an open access article distributed under the terms and conditions of the Creative Commons Attribution (CC-BY) license (http:/ / creativecommons.org/licenses/by/4.0/). 